\title{
Association of iRhom1 and iRhom 2 expression with prognosis in patients with cervical cancer and possible signaling pathways
}

\author{
QIN XU ${ }^{1}$, CHUANBEN CHEN $^{2}$, BIN LIU $^{1}$, YIBIN LIN $^{1}$, PENG ZHENG $^{2}$, DONGMEI ZHOU $^{3}$, \\ YUNQING XIE ${ }^{4}$, YALIN $^{2}$, CIREN GUO $^{1}, \mathrm{JING} \mathrm{LIU}^{1}$ and $\mathrm{LI} \mathrm{LI}^{1}$ \\ Departments of ${ }^{1}$ Gynecology, ${ }^{2}$ Oncology, ${ }^{3}$ Research Pathology and ${ }^{4}$ Research Center, Fujian Cancer Hospital, \\ Teaching Hospital of Fujian Medical University, Fuzhou, Fujian 350014, P.R. China
}

Received April 5, 2019; Accepted September 20, 2019

DOI: $10.3892 / o r .2019 .7389$

\begin{abstract}
Several proteins in the iRhom family function as oncogenic regulators in certain cancers. However, the function of these proteins in cervical cancer (CC) is unknown. The relationship of iRhom 1 and iRhom 2 expression with the clinicopathological features and prognosis of patients with CC was investigated, and their possible molecular mechanisms were examined using in vitro experiments. The expression of iRhom 1 and iRhom 2 in CC samples of 83 patients was determined by immunohistochemistry (IHC), and the associations of their expression with the clinicopathological features of patients were determined. The relationship of iRhom1, iRhom2, and Ki-67 expression with survival rates was determined using Kaplan-Meier analysis and Cox regression analyses. HeLa cells were analyzed using MTT assays, cell cycle analysis, and apoptosis assays. The results revealed that $\mathrm{CC}$ tissues had higher levels of iRhom 1 and iRhom 2 than adjacent normal tissues. Increased expression of iRhom1, iRhom2, and K-i67 was significantly associated with tumor stage, size, and parametrium invasion. High expression of iRhom1, iRhom 2 and Ki-67 was correlated with poor outcomes. Cancer stage and iRhom 2 expression were independent prognostic indicators of CC. Knockdown of iRhoml and iRhom 2 in HeLa cells inhibited cell proliferation, promoted the G1 phase and relieved S-phase arrest, and induced apoptosis. Genomic microarray analysis indicated that $i$ hhom 2 knockdown altered several pathways with roles in oncogenesis, including the expression of five genes in the $\mathrm{Wnt} / \beta$-catenin pathway. Western blotting in HeLa cells revealed that iRhoml knockdown significantly suppressed the expression of $\beta$-catenin, Myc, p-EGFR and TGFBR2, and increased the expression of FAS; iRhom 2 knockdown significantly suppressed the expression
\end{abstract}

Correspondence to: Dr Chuanben Chen, Department of Oncology, Fujian Cancer Hospital, Teaching Hospital of Fujian Medical University, 420 Fuma Road, Fuzhou, Fujian 350014, P.R. China E-mail: xq1379423879@163.com

Key words: iRhom1, iRhom2, uterine cervical cancer, prognostic biomarker, Wnt/ $\beta$-catenin pathway, genomic microarray of $\beta$-catenin, GSK3 $\beta$, p-EGFR and Myc. These results were consistent with the genomic microarray data. Collectively, the results indicated that iRhoml and iRhom 2 may function as oncogenes in $\mathrm{CC}$ and are potential therapeutic targets.

\section{Introduction}

Cervical cancer (CC) is among the most common cancers in women worldwide. It mostly affects women in poor countries that lack public health infrastructures, CC screening, and vaccines against the human papillomavirus (HPV). In 2016, 511,000 women [95\% confidence interval (CI), 414,000-542,000] developed CC, and 247,000 women (95\% CI, 204,000-263,000) succumbed to CC worldwide (1). Radical surgery and radiotherapy are well-established and effective; however, tumors recur or progress in $>30 \%$ of patients $(2,3)$. The risk factors for CC are well known, but few targeted therapies are available. Thus, it is important to identify the genetic and molecular abnormalities underlying $\mathrm{CC}$ for the development of new and effective therapies.

Rhomboid genes were first described in Drosophila melanogaster, where they function as serine proteases and key regulators of epidermal growth factor receptor (EGFR) signaling (4). The inactive rhomboid protein 1 (iRhom1 or RHBDF1) is a member of the rhomboid family that lacks protease activity. This protein traverses the membrane 7 times, and has a long $\mathrm{N}$-terminal cytoplasmic extension that comprises approximately half of the polypeptide sequence. This protein occurs in the endoplasmic reticulum and Golgi apparatus, rather than the plasma membrane. Several recent studies demonstrated that iRhom 1 functions as an oncogene in head and neck neoplasms (5), breast (6) and colorectal cancer (7). Molecular studies reported that iRhom1 has a critical function in G-protein coupled receptor (GPCR) ligand-stimulated processes that activate EGFR ligands in head and neck squamous cancer cells (5) and breast cancer (6). Overexpression of iRhom1 was revealed to have a significantly positive correlation with poor overall survival (OS) in patients with colorectal cancer (7).

Inactive rhomboid protein 2 (iRhom 2 or RHBDF2) is also a catalytically inactive member of the rhomboid family. This protein mediates the maturation of TNF $\alpha$ converting enzyme (TACE, also called ADAM17) and trafficking to the 
cell surface (8). iRhom2 functions as an essential endoplasmic reticulum-to-Golgi trafficking factor for metalloproteinase ADAM17 when macrophages secrete $\mathrm{TNF} \alpha(9,10)$. We previously demonstrated that ADAM17 expression was an independent prognostic indicator for CC (11). In esophageal cancer, the hyperproliferative phenotype was revealed to be associated with altered iRhom2 levels and increased EGFR signaling $(12,13)$. Identification of a novel p63-associated pathway indicated that therapeutic modulation of iRhom 2 has potential for treatment of hyperproliferative skin disease and neoplasia (14). Blaydon et al recently reported that missense mutations in iRhom 2 were responsible for the autosomal dominant condition tylosis with oesophageal cancer (TOC) in three families from the United Kingdom, United States and Germany (10). Cancer-associated fibroblasts (CAFs) promote tumorigenesis in several types of cancers. iRhom 2 overexpression was revealed to occur in CAFs isolated from human diffuse-type gastric cancers (15). However, the levels and roles of iRhom1 and iRhom 2 in the onset and progression of $\mathrm{CC}$ remain unknown.

In the present study, the expression of iRhom1 and iRhom 2 in CC clinical samples was first assessed. Then, their associations with the clinicopathological features of the $\mathrm{CC}$ patients were determined and their prognostic value was assessed. Subsequently, HeLa cells were used to evaluate the effects of knockdown of iRhom 1 and iRhom 2 on cell proliferation, cell cycle distribution, and apoptosis. Finally, microarray analysis was used to identify the molecular mechanisms responsible for iRhom-mediated promotion of CC by examination of pathways that have critical roles in the development and progression of CC.

\section{Materials and methods}

Patients and tissue collection. The Ethics Committee of Fujian Provincial Cancer Hospital, which is affiliated with Fujian Medical University, provided approval of this study. Samples from 83 consecutive patients (age range, 32-80 years) with $\mathrm{CC}$ were collected for immunohistochemical (IHC) analysis from January 2010 to December 2012. Prior to surgery, none of the enrolled patients received chemotherapy or radiotherapy. Cancer classification followed the 2009 Federation International of Gynecology and Obstetrics (FIGO) protocol, and enrolled patients were followed-up until December 2017 or death. Eligibility was determined following hysterectomy (total, modified-radical, or radical), bilateral salpingo-oophorectomy, pelvic lymphadenectomy, or para-aortic lymphadenectomy. Surgical staging was performed no more than 8 weeks before initiation of radiotherapy. The included patients had hematological, liver, renal function, and other laboratory variables within normal ranges (creatinine clearance $\geq 40 \mathrm{ml} / \mathrm{min}$, leucocytes $\geq 4.0 \times 10^{9} / 1$, platelets $\geq 100 \times 10^{9} / 1$, and hemoglobin $\geq 10 \mathrm{~g} / \mathrm{dl}$ ). Any patient with a secondary malignancy, a serious concomitant systemic disorder, or a psychiatric disease was deemed ineligible. For validation of each diagnosis, two independent pathologists evaluated the IHC results. After patients provided written informed consent, samples were used for analysis. Twenty fresh CC tissues specimens (11 from squamous cell carcinomas, 5 from adenocarcinomas, 1 from small-cell carcinoma, and 3 from adenosquamous carcinomas) and matching non-cancerous adjacent cervical tissue samples were used for immunoblotting.

Study endpoints. Progression-free survival (PFS, the duration from enrollment to disease progression or death) was the primary endpoint, and local-regional failure, distant failure, and OS were the secondary endpoints.

Reagents. The following antibodies were obtained from Abcam: iRhom1 (ID product code ab81342), iRhom2 (ID product code ab116139), Ki67 (ID product code ab92742), $\beta$-catenin (ID product code ab32572), Fas (ID product code ab82419), GSK3B (ID product code ab32391), Myc (ID product code ab32), TGFBR2 (ID product code ab78419), EGFR (ID product code ab52894), p-EGFR (ID product code ab40815), GADPH (ID product code ab8245), and actin (ID product code ab179467). Horseradish peroxidase (HRP)-labeled secondary antibodies (ID product code sc-2354 and sc-2357) were purchased from Santa Cruz Biotechnology, Inc.

Immunohistochemistry. IHC analyses employed formalin-fixed and paraffin-embedded $5 \mu \mathrm{m}$-thick sections. These sections were deparaffinized in xylene and rehydrated in a graded series of alcohol. For labeling, the avidin-biotin complex (ABC) method was used. For antigen retrieval, a steamer was used for $20 \mathrm{~min}$ in an EDTA buffer. Then, samples were treated with $3 \%$ hydrogen peroxide in methanol for 20 min to block endogenous peroxidase activity and the reaction was blocked for $1 \mathrm{~h}$ by incubation in a $5 \%$ solution of non-fat milk. Slides were then incubated with polyclonal rabbit antibodies against the iRhom1 (1:50 dilution), iRhom2 (1:50 dilution), or Ki67 (1:100 dilution) antibody at room temperature for $1 \mathrm{~h}$. The secondary antibody (MaxVision HRP-polymer anti-rabbit; Fuzhou Maixin-Biotech Co., Ltd.) was added, and counterstaining was performed using Mayer's hematoxylin and diaminobenzidine. Tumor cells that had staining in the cytoplasm were considered iRhom1- or iRhom2-positive, and tumor cells that had staining in the nucleus were considered Ki67-positive.

For IHC analysis of iRhom1, iRhom 2 and Ki-67, images of five typical visual fields of each section were analyzed using software (Image-Pro Plus 6.0; Media Cybernetics, Inc.), and the mean absorption was used to score expression. All sections were scored separately by two pathologists who were unaware of the clinical parameters of the corresponding patients. Stain intensity was scored as 0 (negative), 1 (weak), 2 (strong). The percentage of positively-stained area was 0 (fewer than $10 \%$ positive cells), 1 (10 to $25 \%$ positive cells), 2 (26 to $50 \%$ positive cells), and 3 (50\% or more positive cells). The final score was determined from the average of products in stain intensity and percentage with staining that were immunoreactive on the cell membranes and/or cytoplasm by examination of 10 typical microscopic fields. The final IHC score was defined as 0 (-, negative expression), 1-2 (+, weak expression), 3-4 (++, medium expression), 5-6 (+++, strong expression).

Cell culture. HeLa cells (Chinese Academy of Sciences Cell Bank) were plated in 6 -well plates $\left(\sim 2 \times 10^{6}\right.$ cells/well $)$, in Dulbecco's modified Eagle's medium with $10 \%$ fetal bovine serum (FBS; $1 \mathrm{ml} /$ well). These cells were grown at $37^{\circ} \mathrm{C}$ with $5 \% \mathrm{CO}_{2}$ and $95 \%$ air. After $24 \mathrm{~h}$, cell attachment had 
occurred and cells were then incubated in SBF-free medium for 16 to $18 \mathrm{~h}$.

Recombinant lentiviral vector construction and cell infection. Short hairpin RNAs (shRNAs) that targeted the iRhoml gene (NM_022450.3) and iRhom 2 gene (NM_024599.5) were designed, and lentiviruses were constructed to knockdown these genes. The shRNA targeting iRhoml was GAGGCT GGCGGAAGCAGAA, the shRNA targeting iRhom 2 was CGTGTCTGTGGTCTTTCAA, and the negative control (NC) sequence was TTCTCCGAACGTGTCACGT. Related stem-loop DNA oligonucleotides were prepared and inserted into a lentiviral vector (pGCSIL-GFP; Shanghai GeneChem Co., Ltd.). The Lentivector Expression System (Shanghai GeneChem Co., Ltd.) was used to produce lentiviruses expressing iRhoml shRNA, iRhom 2 shRNA, or NC shRNA.

Infection of HeLa cells with lentivirus. HeLa cells were grown in 12-well plates, then infected with a shRNA-expressing lentivirus, according to the desired multiplicity of infection (MOI). Cells were then observed using fluorescence microscopy (MicroPublisher 3.3RTV; Olympus Corp.) at 72 h. Cells were harvested at $120 \mathrm{~h}$ to determine knockdown efficiency using immunoblotting.

Western blotting. Samples were initially added to a radio-immunoprecipitation buffer (Beyotime Institute of Biotechnology) with $100 \mathrm{nM}$ phenylmethylsulfonyl fluoride (PMSF). After assessment of protein concentrations with a bicinchoninic acid kit (Pierce; Thermo Fisher Scientific, Inc.), proteins (50 $\mu \mathrm{g}$ per lane) were separated by electrophoresis on $12 \%$ SDS-PAGE gels, and then transferred to PVDF membranes (EMD Millipore). These membranes were incubated with the primary antibody such as iRhom1 (1:50 dilution), iRhom2 (1:50 dilution), $\beta$-catenin (1:1,000 dilution), Fas (1:150 dilution), GSK3B (1:100 dilution), Myc (1:1,000 dilution), TGFBR2 (1:100 dilution), EGFR (1:1000 dilution), p-EGFR (1:1,000 dilution), GADPH (1:1,500 dilution) and actin (1:1,500 dilution) in Tris-buffered saline with $0.05 \%$ Tween-20 and $5 \%$ non-fat dry milk. After incubation at room temperature for $2 \mathrm{~h}$, the membranes were washed, and then incubated with the HRP-labeled secondary antibody (1:2,000 dilution) at room temperature for $1 \mathrm{~h}$. Electrochemiluminescence (Elecsys 2010; Roche Diagnostics, Basel, Switzerland) was used for visualization of proteins. Image Lab version 3.0 software was used to perform the densitometric analysis of blots.

MTT assay. Transfected HeLa cells were added to a 96-well plate $\left(1 \times 10^{4}\right.$ cells/well $)$ and incubated for 24, 48, 72 and $96 \mathrm{~h}$. Then MTT (10 $\mu \mathrm{l} ; 5 \mathrm{mg} / \mathrm{ml})$ in PBS (pH 7.4, Sigma-Aldrich; Merck KGaA) was added to each well for $4 \mathrm{~h}$. After removal of the supernatant, dimethyl sulfoxide (DMSO, $100 \mu \mathrm{l} /$ well; Thermo Fisher Scientific, Inc.) was added and the absorbance was measured at $490 \mathrm{~nm}$ using a microplate reader. Each experiment was performed in triplicate, and each measurement was also performed in triplicate.

Cell cycle analysis. Approximately $1 \times 10^{6} \mathrm{HeLa}$ cells were treated with trypsin, washed twice in PBS, and then incubated overnight in $10 \mathrm{ml}$ of cold ethanol. Cells were then centrifuged with $1,000 \mathrm{x} \mathrm{g}$ and the ethanol was removed. They were then washed twice in PBS, added to $100 \mu 1 \mathrm{RNase}\left(30 \mathrm{~min}\right.$ at $37^{\circ} \mathrm{C}$ ), and then centrifuged at $1,000 \mathrm{x}$. The pellet was added to $400 \mu \mathrm{l}$ propidium iodide, and allowed to stand in darkness for 30 min at $4^{\circ} \mathrm{C}$. The BD FACSCalibur system (BD Biosciences) was then used for flow cytometry and analysis of cell cycle distribution.

Clone formation assay. For each group, $\sim 1 \times 10^{4} \mathrm{HeLa}$ cells were added to each well of a 6 -well culture plate (3 wells/group). The cells were incubated for 14 days at $37^{\circ} \mathrm{C}$, and the growth medium was replaced every 3 days. After 14 days, the cells were washed two times with PBS and $0.5 \%$ crystal violet was added for staining in 5 min under ambient temperature. Microscopy (light, 10x10) was used to determine the number of colonies that had at least 50 cells. The efficiency of plate clone formation was defined as $100 \% \mathrm{x}$ (number of colonies/number of cells inoculated), and there were 3 replicates per experiment.

Cell apoptosis assay with Annexin V-APC single-color staining. After collection of HeLa cells $\left(\sim 2 \times 10^{5}\right)$, allophycocyanin (APC)-labeled Annexin V (cat. no. 88-8007; eBioscience) were added for single-color staining to detect apoptotic (Annexin V positive) cells. A total of $1.0 \times 10^{6}$ cells were washed twice with pre-cooled PBS (pH 7.4), and incubated for $15 \mathrm{~min}$ in $100 \mu \mathrm{l}$ staining buffer including $5 \mu \mathrm{l}$ APC-labeled Annexin V. FACS analysis for Annexin V staining was subsequently performed by flow cytometry (FACSCalibur; BD Biosciences).

Microarray processing and analysis. Total RNA was extracted from HeLa cells that were infected with lentivirus expressing $N C /$ shRNA $(\mathrm{n}=3)$ or $i R h o m 2 / \operatorname{shRNA}(\mathrm{n}=3)$ by use of the TRIzol reagent. RNA was assessed using the Thermo NanoDrop 2000 and Agilent 2100 Bioanalyzer. Microarray processing and measurement of gene expression profiles were performed using the Affymetrix human GeneChip primeview (Affymetrix Inc.; Thermo Fisher Scientific, Inc.), using the manufacturer's protocols. The GeneChip 3' IVT Expression Kit was used to perform reverse transcription, dsDNA template transformation, in vitro transcription, and biotin labeling. The GeneChip Hybridization Wash and Stain Kit was then used to perform microarray hybridization, washing, and staining. Finally, the GeneChip Scanner 3000 was employed to perform scanning of the arrays and to produce the raw data.

Integrative analyses. The integrative analyses were generated using Ingenuity Pathway Analysis (IPA; Ingenuity Systems ${ }^{\circledR}$; www.ingenuity.com). A file that had 596 gene IDs and mean $\log _{2}$ (fold-change) data was uploaded to identify canonical pathways, upstream regulators, relationships with cellular functions and diseases, effects on regulators, and network analysis. A P-value and a Z-score were determined for each pathway/network so that random data had a low probability of producing significant predictions. The P-value (from a right-sided Fisher's exact test) considers the number of input genes and the number of molecules in the database that could be in networks. The Z-score indicates activation or inhibition of a pathway/network. The IPA database is based on experiments and results published in numerous professional journals. The final graphical representation of each pathway/network 
has nodes (genes) and edges (biological relationships between nodes), with unique symbols used for different classes of molecules.

Statistical analyses. The statistical analyses were performed using SPSS (version 19.0; IBM Corp.). The correlations in the expression of different markers were evaluated using Pearson's coefficient, and the Chi-square test was used to calculate the statistical significance of differences between groups. Kaplan-Meier survival curves were plotted, and the log-rank test was used to determine the significance of differences between these curves. A multivariate analysis (Cox's non-parametric model) was performed to assess the relationship of iRhom1, iRhom 2 and $\mathrm{Ki}-67$ expression on progression-free survival (PFS) and overall survival (OS). The results from western blotting experiments (means \pm standard deviations) were obtained from at least three independent experiments. The statistical significance of differences was determined using Student's t-test and a one-way analysis of variance (ANOVA) with post hoc Student-Newman-Keuls test. For all data, a P-value $<0.05$ was considered to indicate a statistically significant difference.

\section{Results}

Expression of $i R h o m 1$, iRhom 2 and $K i-67$. Tissue specimens from $83 \mathrm{CC}$ patients were examined using IHC analysis for iRhom1, iRhom 2 and Ki-67.iRhoms (-/+) and iRhoms (++/+++) were based on the average of products in stain intensity and percentage of positively-stained area. Pathological analysis indicated squamous cell carcinomas $(n=44)$, adenocarcinomas $(n=29)$, small-cell carcinomas $(n=4)$, and adenosquamous carcinomas $(n=6)$. iRhom1 and $i R h o m 2$ were present in the cytoplasm of tumor cells, and Ki67 was mainly in the nucleus, as indicated by dark yellow granules (Fig. 1A). There was high expression of iRhom1 in 55 out of the 83 cases $(66.3 \%)$, of iRhom 2 in 49 out of the 83 cases (59.1\%), and of Ki-67 in 48 out of the 83 cases $(57.8 \%)$ (Table I).

The possible function of iRhom 1 and iRhom 2 was investigated in $\mathrm{CC}$ tumorigenesis by performing western blotting of normal cervical tissues and adjacent fresh CC tissues. The results indicated that iRhom 1 and iRhom 2 had higher expression in $\mathrm{CC}$ tissues than adjacent noncancerous tissues (Fig. 1B, $\mathrm{P}<0.001$ ).

Correlation of iRhom1, iRhom 2 and Ki-67 with demographic and clinical factors. The correlations of expression of iRhom1, iRhom 2 and Ki-67 with various clinical factors were examined (Table I). All three proteins had a significant association with FIGO stage $\left(\mathrm{P}_{\mathrm{iRhom} 1}=0.042 ; \mathrm{P}_{\mathrm{iRhom} 2}=0.010 ; \mathrm{P}_{\mathrm{Ki}-67}<0.001\right)$. There was also a significant association between $\mathrm{Ki}-67$ expression and lymph node metastasis $(\mathrm{P}=0.002)$, and significant associations of $\mathrm{iRhom} 1$ expression with parametrium invasion $(\mathrm{P}=0.039)$ and tumor size $(\mathrm{P}=0.04)$.

Correlation of iRhom1, iRhom 2 and $\mathrm{Ki}-67$ with clinical outcomes. Kaplan-Meier analysis was also used to determine the independent prognostic value of iRhom1, iRhom2, and Ki-67 on PFS and OS (Fig. 2). iRhoms (-/+) represented weak expression and iRhoms $(++/+++)$ represented strong expression. The results revealed that patients with strong expression of each protein had a significantly worse PFS than those with weak expression $\left(\mathrm{P}_{\mathrm{iRhom} 1}=0.018 ; \mathrm{P}_{\mathrm{iRhom} 2}=0.002\right.$; $\mathrm{P}_{\mathrm{Ki}-67}=0.022$ ). In addition, patients with strong expression of each protein had significantly worse OS than those with weak expression $\left(\mathrm{P}_{\mathrm{iRhom} 1}=0.026 ; \mathrm{P}_{\mathrm{iRhom} 2}=0.001 ; \mathrm{P}_{\mathrm{Ki}-67}=0.031\right)$.

Multivariate analysis of prognostic variables. multivariate Cox regression analysis was used to examine the relationship of OS with iRhom1, iRhom2, Ki-67, age, histology, stage, metastases to lymph nodes, and invasion of the parametrium (Table II). The results indicated that iRhom 2 expression [hazard ratio $(\mathrm{HR})=4.374 ; \mathrm{P}=0.033 ; 95 \%$ confidence interval $(\mathrm{CI})=1.130-16.937]$ and FIGO stage $(\mathrm{HR}=1.778 ; \mathrm{P}=0.027$; 95\% CI=1.069-2.598) were statistically significant and independent prognostic factors (Table II). Multivariate analysis of PFS indicated that $\mathrm{iRhom} 2$ expression $(\mathrm{HR}=4.074 ; \mathrm{P}=0.036$; 95\% $\mathrm{CI}=1.097-15.129)$ and FIGO stage $(\mathrm{HR}=1.892 ; \mathrm{P}=0.014$; $95 \% \mathrm{CI}=1.137-3.147$ ) were also statistically significant and independent prognostic factors (Table II).

Oncogenic roles of iRhoml and iRhom 2 knockdown in HeLa cells. Next, transfected HeLa cells were used to examine the effect of knockdown of iRhoml and iRhom 2 on CC cell proliferation in vitro. The reduced expression of each protein in these cells confirmed the efficiency of silencing (Fig. 3A). In particular, each shRNA knocked down expression by $>50 \%$. The MTT assay indicated that cell viability in the controls $\left(\mathrm{OD}_{490 \mathrm{~nm}}\right)$ was greater than in cells with knockdown of $i$ Rhoml or $i$ Rhom 2 from day 1 to day 5, and that iRhom 2 knockdown had a stronger effect than iRhoml knockdown (Fig. 3B). Moreover, knockdown of each gene significantly decreased the formation of cell colonies (Fig. 3C).

The effect of knockdown of iRhoml and iRhom 2 was also determined on apoptosis using Annexin V-APC staining and flow cytometry (Fig. 4A). In these assays, cells in the upper right quadrant (necrotic) and the lower right quadrant (apoptotic) were apoptotic (Annexin V positive). The results revealed that knockdown of iRhom1 or iRhom 2 significantly increased the percentages of cells in apoptosis (Fig. 4A). Dysregulation of the cell cycle in tumors helps to sustain cell proliferation. Thus, flow cytometry was used to identify the effects of $i$ Rhoml and iRhom 2 knockdown on HeLa cell cycle progression (Fig. 4B). The results revealed that downregulation of $i$ Rhom 1 or $i$ Rhom 2 induced cell cycle arrest at the G1 phase, thus, there was a considerable decrease in the percentage of cells in the $\mathrm{S}$ phase and an increase in the percentage of cells in G1-phase relative to control cells (Fig. 4B). However, overexpression of iRhom1 and iRhom 2 facilitated cell proliferation of cervical cancer.

Pathways and genes affected by iRhom 2 knockdown. HeLa cells were used infected with iRhom $2 /$ shRNA or NC/shRNA and a microarray platform for genome-wide gene expression profiling (Fig. 5). The results revealed that iRhom 2 knockdown led to significant differences in the expression of 596 genes $[\mathrm{P}<0.05$ for absolute fold change ( $\mathrm{FC}$ absolute) $>1.5]$, with 147 upregulated genes and 449 downregulated genes (Fig. 5A). Use of the IPA system for analysis of the microarray data revealed that $i$ Rhom 2 knockdown led to dysregulation of several cellular and molecular functions, including impairment 


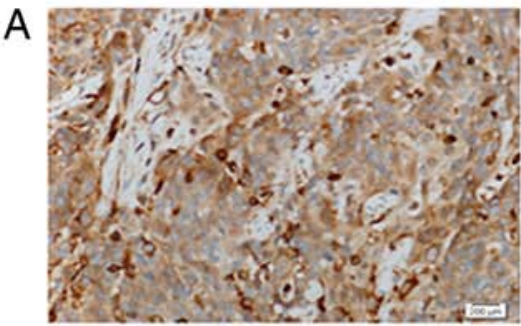

iRhom1

$(40 \mathrm{X})$

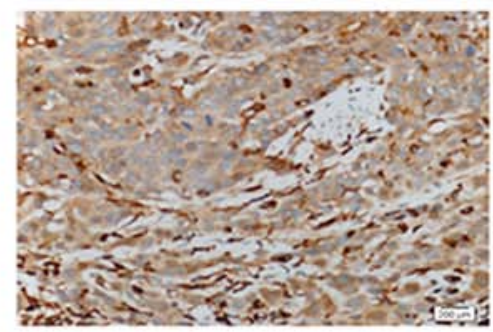

iRhom2

$(40 \mathrm{X})$

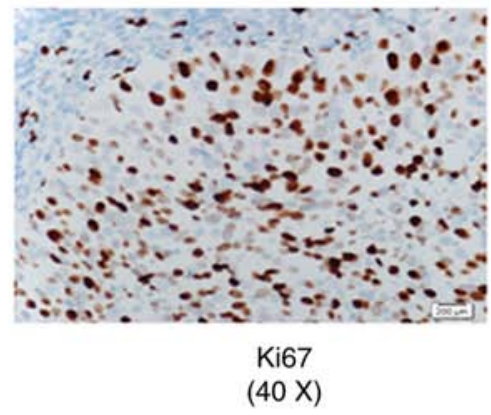

$(40 \mathrm{X})$
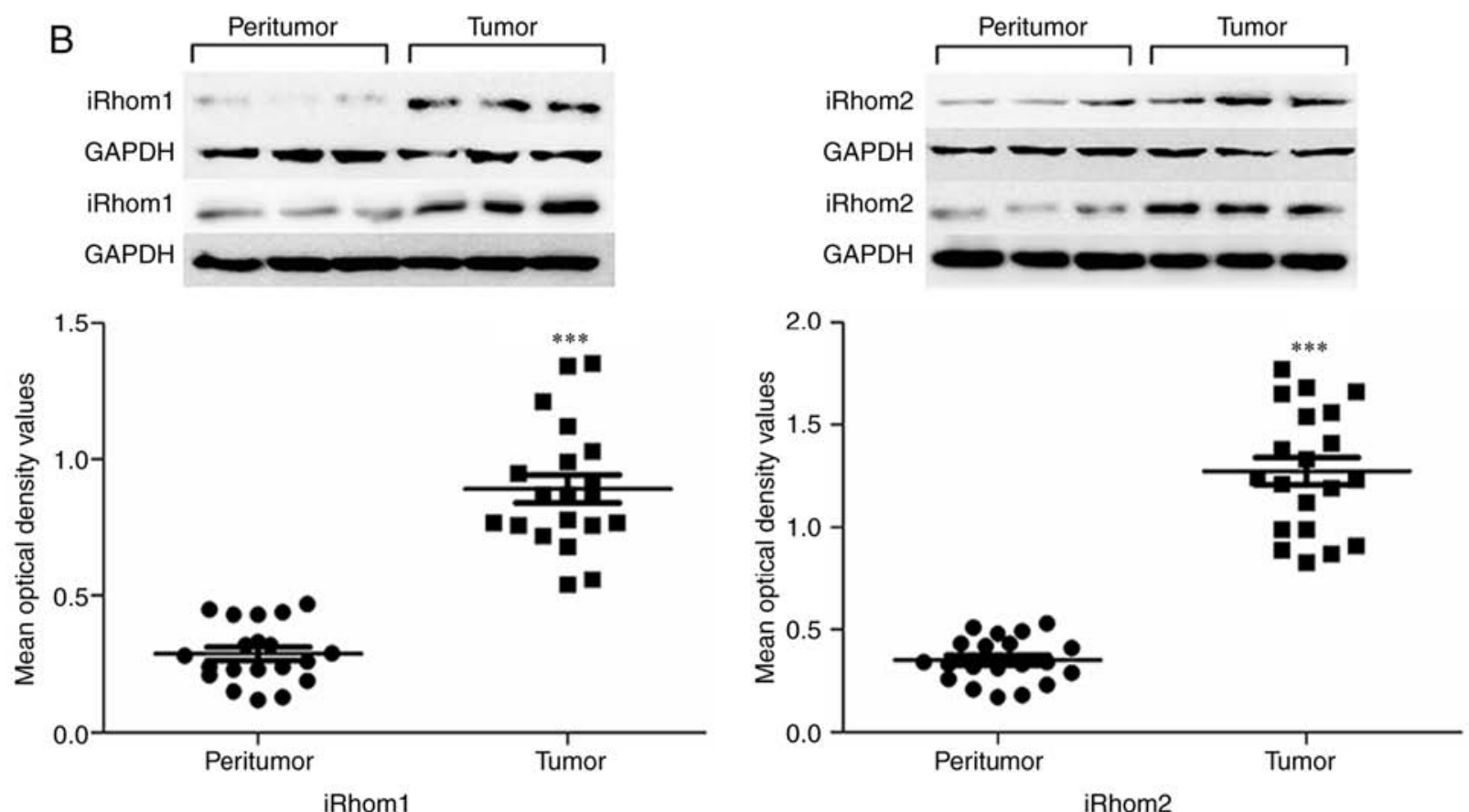

Figure 1. Expression of iRhom1, iRhom2 and Ki-67 in cancerous tissues and adjacent normal tissues of patients with CC. (A) Representative photomicrographs (40X) of CC specimens stained with anti-iRhom1, anti-iRhom 2 and anti-Ki67 antibodies. iRhom1 and iRhom 2 were in the cytoplasm, and Ki-67 was mainly in the nucleus, as indicated by dark-yellow granules. (B) Quantitation of results, revealing increased levels of iRhom1 and iRhom 2 in cancerous tissues relative to paired adjacent non-cancerous tissues $\left({ }^{* * *} \mathrm{P}<0.001\right)$. iRhom1, inactive rhomboid protein 1 ; iRhom2, inactive rhomboid protein 2 ; CC, cervical cancer.

of cell death and survival, cell growth and proliferation, cancer, neurological disease, immunological disease, metabolic disease and cell cycle progression (Fig. 5C). The 'canonical pathway' module was also used for further analysis of the microarray data and downstream pathways that function in carcinogenesis (STAT3, PI3K/AKT, Wnt/ $\beta$-catenin, PTEN, mTOR, unfolded protein response signaling, Fig. 5B) were identified. This analysis considers a pathway to be inhibited when the IPA $Z$-score is negative. The results indicated significant inhibition of Wnt $/ \beta$-catenin signaling, which had an IPA Z-score of -1.134 (Fig. 5D).

Effect of iRhom 1 and iRhom 2 knockdown on the Wnt/ $\beta$-catenin pathway. The present results revealed that expression of iRhom1 and iRhom 2 are linked to carcinogenesis and aggressiveness of CC cells in vitro, however, the mechanisms of this effect have not been systematically investigated. The results from the IPA system indicated that $i R h o m 2$ knockdown affected several proteins that function in Wnt/ $\beta$-catenin signaling (Table III). This pathway has well established roles in the migration and invasion of tumor cells.
Thus, the effect of iRhoml and iRhom 2 knockdown on the Wnt/ $\beta$-catenin signaling in HeLa cells was also determined by assessing the expression of several key proteins in this pathway (Fig. 6). The western blotting results indicated that iRhoml silencing decreased the expression of $\beta$-catenin, Myc, p-EGFR and TGFBR2, and increased the expression of FAS $(\mathrm{P}<0.05$ for each comparison); iRhom 2 silencing significantly decreased the expression of $\beta$-catenin, GSK3 $\beta$, p-EGFR and Myc $(\mathrm{P}<0.05$ for each comparison).

\section{Discussion}

$\mathrm{CC}$ is a common gynecological cancer. An improved molecular understanding of its onset and pathogenesis is urgently required to develop better treatments. The impact of iRhom proteins on survival from malignant $\mathrm{CC}$ has not yet been fully clarified. To the best of our knowledge, no previous studies have examined the expression of iRhom proteins in CC, nor examined the prognostic value of iRhom1 and iRhom 2 expression. The present western blot analyses of CC and adjacent non-malignant normal tissues revealed that iRhom1 and iRhom 2 were 


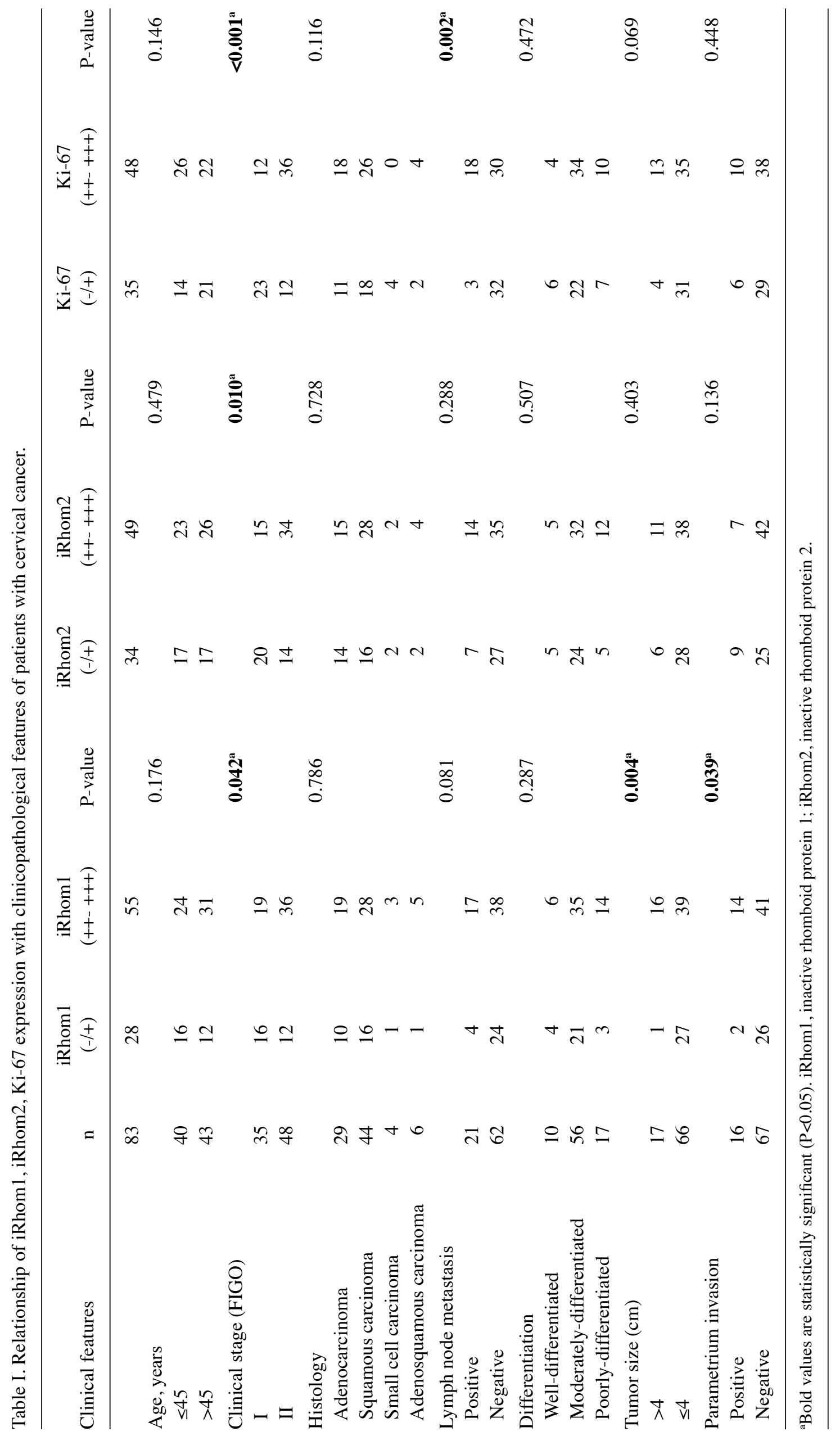



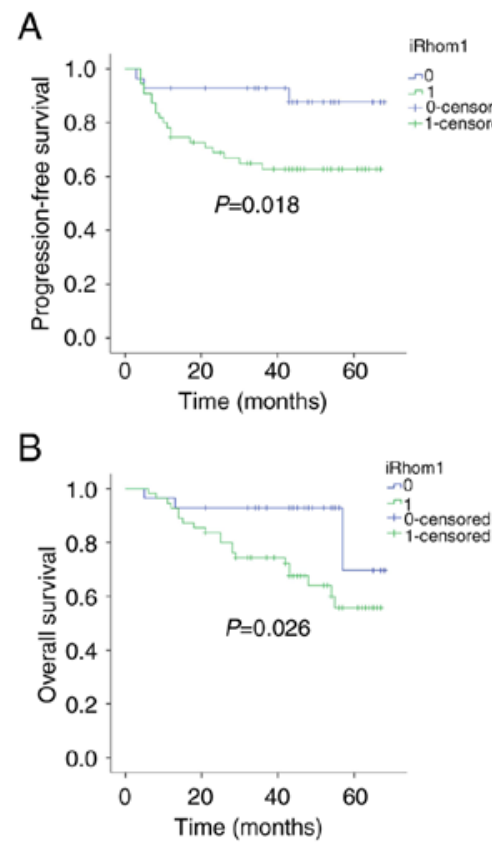
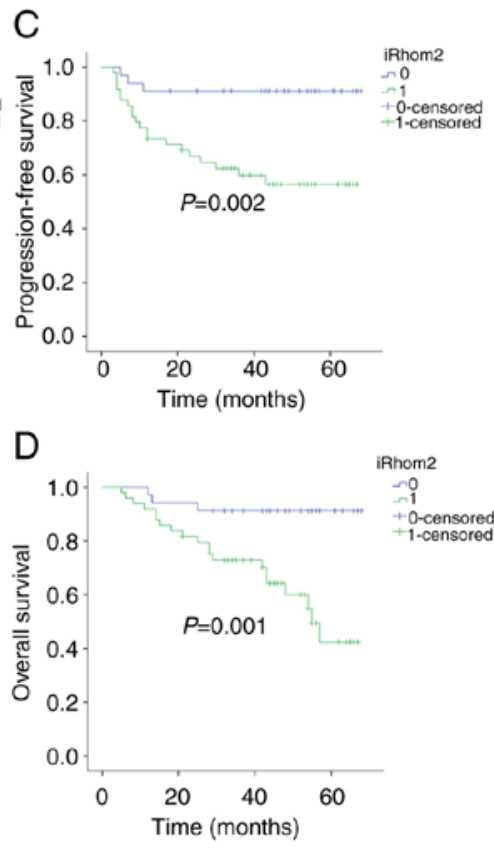
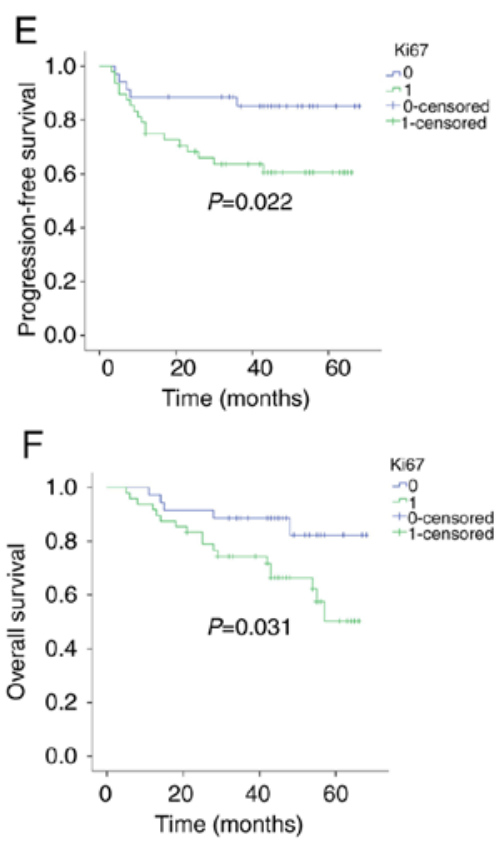

Figure 2. Kaplan-Meier analysis of PFS and OS with stratification by expression of iRhom1, iRhom2, and Ki-67 in patients with CC (n=83). (A and B) Strong expression $(++/+++)$ of iRhom1 was associated with poor PFS $(\mathrm{P}=0.018)$ and poor OS $(\mathrm{P}=0.026)$. (C and $\mathrm{D})$ Strong expression $(++/+++)$ of iRhom 2 was associated with poor PFS $(\mathrm{P}=0.002)$ and poor OS $(\mathrm{P}=0.001)$. (E and $\mathrm{F})$ Patients with strong expression $(++/+++)$ of $\mathrm{Ki67}$ had poor $\mathrm{PFS}(\mathrm{P}=0.022)$ and poor OS ( $\mathrm{P}=0.031)$. PFS, progression-free survival; OS, overall survival; iRhom1, inactive rhomboid protein 1; iRhom2, inactive rhomboid protein 2; CC, cervical cancer.

upregulated in tumors. Additionally, the IHC results indicated positive associations of iRhom1, iRhom2, and Ki-67 expression with cancer stage, tumor size, parametrium invasion, and patient survival. Multivariate analysis indicated that cancer stage and iRhom 2 expression were independent prognostic indicators for CC. Previous research reported that expression of iRhom1 was significantly elevated in clinical specimens of early-stage breast cancer (13). In addition, Yuan et al reported that iRhom1 expression was significantly correlated with tumor size, lymph-node invasion, TNM stage, and poor prognosis in colorectal cancer (CRC) (7), similar to our findings for CC. Another study reported that iRhom 2 had low or undetectable expression in most ovarian tumors that were benign or had low malignant potential (LMP), and in a subset of malignant ovarian tumors (TOV800EPT, TOV881MT, TOV908DT, TOV974EPT, and TOV1007EPT) (16). These results indicated that expression of iRhom proteins in tumor cells may be cell-specific.

The present finding of positive correlations of iRhom1 and iRhom 2 expression with several clinicopathological characteristics suggests that these proteins may have roles in the onset or progression of $\mathrm{CC}$. Thus, to confirm the roles of iRhom1 and iRhom 2 in CC, HeLa cells were used to evaluate the effects of $i R h o m 1$ and $i R h o m 2$ knockdown on cell proliferation, cell cycle progression, and apoptosis. The results indicated that knockdown of each mRNA inhibited cell proliferation and induced apoptosis, similar to their effects on CRC (16). To the best of our knowledge, the present study is the first to quantify the function of $i$ Rhoml and iRhom 2 knockdown on the cell cycle of cancer cells. Downregulation of each mRNA induced cell cycle arrest at the G1 phase, and there were therefore fewer cells in the $\mathrm{S}$ phase, and more cells in the G1 phase. These results demonstrated that iRhoml and iRhom 2 function as oncogenes in $\mathrm{CC}$, and therefore may have potential as diagnostic and prognostic biomarkers and as therapeutic targets.

iRhoms1/2 regulated ADAM17-dependent EGFR signaling during mouse development, suggesting that iRhoms $1 / 2$ could emerge as novel targets for treatment of ADAM17/EGFR-dependent pathologies (17). Etheridge et al indicated that mutant iRhom 2 proteins present in TOC patients provide a 'gain-of-function', leading to increased ADAM17-mediated shedding of EGF signaling molecules (including amphiregulin) from the cell surface (18). Overexpression of iRhom1 was revealed to coincide with increased secretion of TGF- $\alpha$ in HeLa cells (5). The Uev1A-Ubc13 complex with CHIP promoted K63-linked ubiquitination of iRhom2, increasing its effect on ADAM17 activation, and subsequently blocking TNF $\alpha$-induced $\mathrm{NF}-\kappa \mathrm{B}$ signaling in HeLa cells (19). Our previous study reported that blockade of ADAM17 decreased the expression of EMMPRIN, p-EGFR, p-ERK, MMP-2, and MMP-9 proteins in $\mathrm{SiHa}$ and HeLa cells (11). In present study, it was demonstrated that p-EGFR was downregulated in HeLa cells with iRhom1 and iRhom 2 knockdown, further indicating the activation of iRhoms1/2-ADAM17-EGFR signaling in cervical cancer. A previous study also demonstrated that iRhom 2 was implicated in epithelial regeneration and cancer growth through constitutive activation of epidermal growth factor receptor (EGFR) signaling (20), indicating the positive link between iRhoms and EGFR signaling (21). Conversely, Vembar and Brodsky revealed that iRhom 1 and iRhom 2 bind to EGF ligands in the ER, downregulate EGFR signaling, and target these ligands for degradation (22). ADAM17 was revealed to bind to iRhom2, and activate Notch signaling in 
Table II. Multivariate analysis of prognostic factors for patients with cervical cancer $(\mathrm{n}=83)$.

\begin{tabular}{|c|c|c|c|}
\hline \multicolumn{4}{|l|}{ OS } \\
\hline Parameters & Hazard ratio & P-value & $95 \% \mathrm{CI}$ \\
\hline $\begin{array}{l}\text { Age, years } \\
\leq 45 \\
>45\end{array}$ & 1.047 & 0.916 & $0.443-2.476$ \\
\hline $\begin{array}{l}\text { Histology } \\
\text { Adenocarcinoma } \\
\text { Squamous carcinoma } \\
\text { Small cell carcinoma } \\
\text { Adenosquamous carcinoma }\end{array}$ & 0.97 & 0.903 & $0.597-1.576$ \\
\hline $\begin{array}{l}\text { Clinical stage (FIGO) } \\
\text { I } \\
\text { II }\end{array}$ & 1.778 & $0.027^{a}$ & $1.069-2.598$ \\
\hline $\begin{array}{l}\text { Lymph node metastasis } \\
\text { Positive } \\
\text { Negative }\end{array}$ & 0.475 & 0.152 & $0.156-1.335$ \\
\hline $\begin{array}{l}\text { Parametrium invasion } \\
\text { Positive } \\
\text { Negative }\end{array}$ & 1.767 & 0.342 & $0.546-5.714$ \\
\hline iRhom1 & 2.737 & 0.119 & $0.771-9.712$ \\
\hline iRhom2 & 4.374 & $0.033^{a}$ & $1.130-16.937$ \\
\hline Ki-67 & 1.904 & 0.251 & $0.634-5.719$ \\
\hline
\end{tabular}

PFS

\begin{tabular}{|c|c|c|c|}
\hline $\begin{array}{l}\text { Age, years } \\
\leq 45 \\
>45\end{array}$ & 1.2 & 0.68 & $0.506-2.846$ \\
\hline $\begin{array}{l}\text { Histology } \\
\text { Adenocarcinoma } \\
\text { Squamous carcinoma } \\
\text { Small cell carcinoma } \\
\text { Adenosquamous carcinoma }\end{array}$ & 0.986 & 0.956 & $0.597-1.630$ \\
\hline $\begin{array}{l}\text { Clinical stage (FIGO) } \\
\text { I } \\
\text { II }\end{array}$ & 1.892 & $0.014^{a}$ & $1.137-3.147$ \\
\hline $\begin{array}{l}\text { Lymph node metastasis } \\
\text { Positive } \\
\text { Negative }\end{array}$ & 0.403 & 0.106 & $0.134-1.213$ \\
\hline $\begin{array}{l}\text { Parametrium invasion } \\
\text { Positive } \\
\text { Negative }\end{array}$ & 1.429 & 0.545 & $0.450-4.539$ \\
\hline iRhom1 & 3.037 & 0.085 & $0.858-10.753$ \\
\hline iRhom2 & 4.074 & $0.036^{a}$ & $1.097-15.129$ \\
\hline Ki-67 & 1.876 & 0.272 & $0.611-5.759$ \\
\hline
\end{tabular}

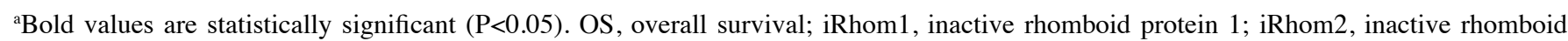
protein 2; PFS, progression-free survival.

lung cancer stem cells (LCSCs). Moreover, iNOS was revealed to have an important role in hepatocellular carcinoma due to its effect on iRhom2/ADAM17 and Notch signaling (23). MET activation in keratinocytes enhanced Src activity and iRhom 


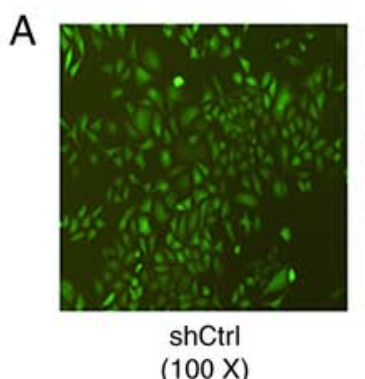

$(100 \mathrm{X})$

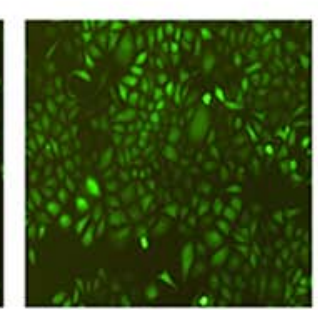

shiRhom1

$(100 \mathrm{X})$

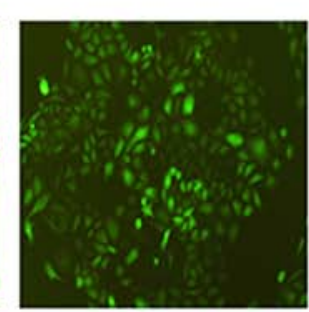

shiRhom2

$(100 \mathrm{X})$
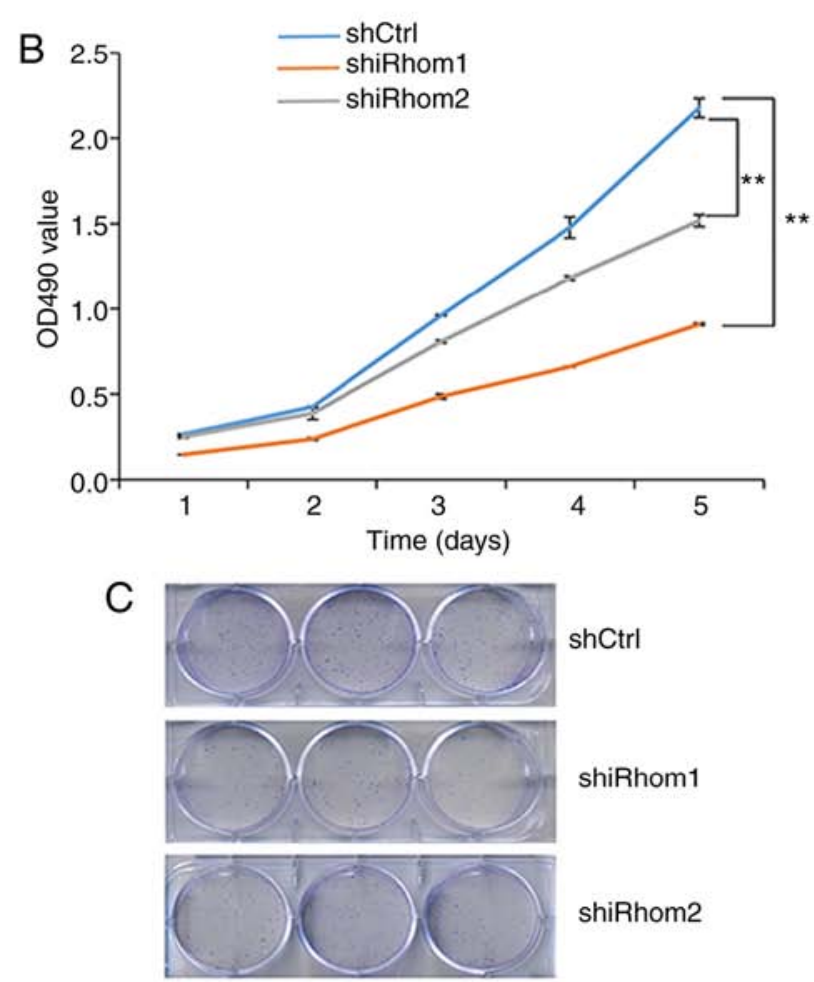
shCtrl

shiRhom1

shiRhom2

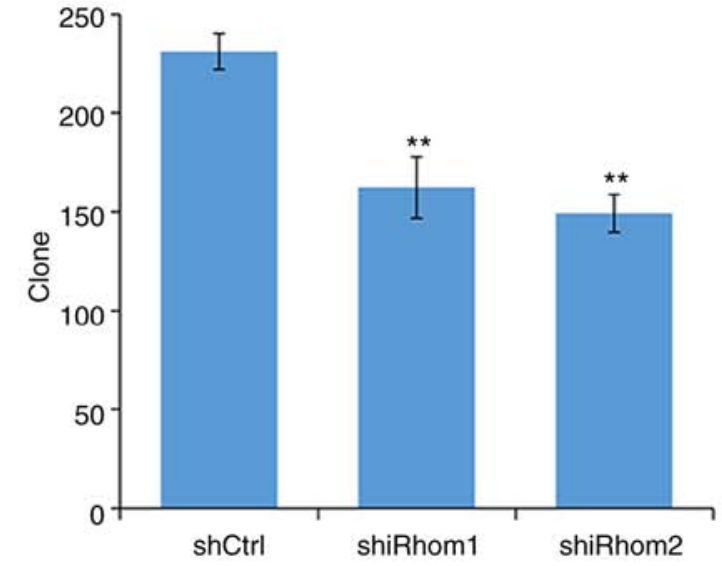

Figure 3. Oncogenic roles of $i R h o m 1$ and $i R h o m 2$ knockdown on HeLa cells. (A) Expression of iRhom 1 and iRhom 2 (western blotting) in cells transfected with iRhoml or iRhom 2 shRNA for $72 \mathrm{~h}$. Knockdown of iRhom 1 suppressed its expression by $80.8 \%\left({ }^{* * *} \mathrm{P}<0.01\right)$ and knockdown of $i$ Rhom 2 suppressed its expression by $72.2 \%\left(^{* * *} \mathrm{P}<0.01\right)$. (B) Changes over time in the viability $\left(\mathrm{OD}_{490}\right.$ in MTT assay) of cells transfected with shCtrl, shRhom1, and shRhom $\left.2{ }^{* *} \mathrm{P}<0.05\right)$. (C) Colonies of cells formed following transfection with shCtrl, shRhom1, and shRhom $2\left({ }^{* *} \mathrm{P}<0.05\right)$. iRhom1, inactive rhomboid protein 1 ; iRhom 2 , inactive rhomboid protein 2 .

expression (particularly iRhom2), and this led to ADAM17 activation, possibly due to translocation and maturation of ADAM17 proteolytic activity in squamous tumors (24). We identified a critical role of iRhom proteins in CC development and progression based on studies of clinical samples and HeLa cells. However, the associated signaling mechanisms remain uncertain.

Genomic microarray analysis of HeLa cells in which iRhom 2 was knocked down was also used. The results indicated this treatment significantly altered the expression of hundreds of genes. The IPA data identified multiple pathways that contribute to the onset and progression of cancer. For instance, knockdown of $i R h o m 2$ enriched the Wnt/ $\beta$-catenin signaling pathway. This pathway has been revealed to play a critical role in cell proliferation, survival, differentiation, and epithelial-mesenchymal transition (EMT) in cancer cells (25-27). Studies of canonical Wnt signaling indicated that cytoplasmic stabilization and nuclear translocation of catenin $\beta 1$ (CTNNB1), a regulator of transcription, has a key role (25). However, in the absence of Wnt ligands, the intracellular levels of $\beta$-catenin are low because of the constitutive activity the ' $\beta$-catenin destruction complex'. This multiprotein complex consists of two tumor suppressors (APC and AXIN1), two serine/threonine kinases (CK1 and GSK3) a protein phosphatase (PP2A), and an E3-ubiquitin ligase ( $\beta$-TrCP) (28). Wnt/ $\beta$-catenin signaling plays an important role in several cancers, including CC (29), lung cancer (30), hepatocellular carcinoma (31), breast cancer (32) and leukemia (33). Although there have not been extensive studies of $\mathrm{Wnt} / \beta$-catenin signaling in $\mathrm{CC}$, there is some evidence of involvement. In particular, previous studies revealed that epigenetic silencing via hypermethylation of the promoters of $S F R P 1, S F R P 2$, and SFRP4 activated the Wnt pathway, and promoted cervical adenocarcinoma progression via activation of EMT $(34,35)$. Another study reported that DKK1 was downregulated in $\mathrm{CC}$, and this activated the $\beta$-catenin pathway (36). However, 
A

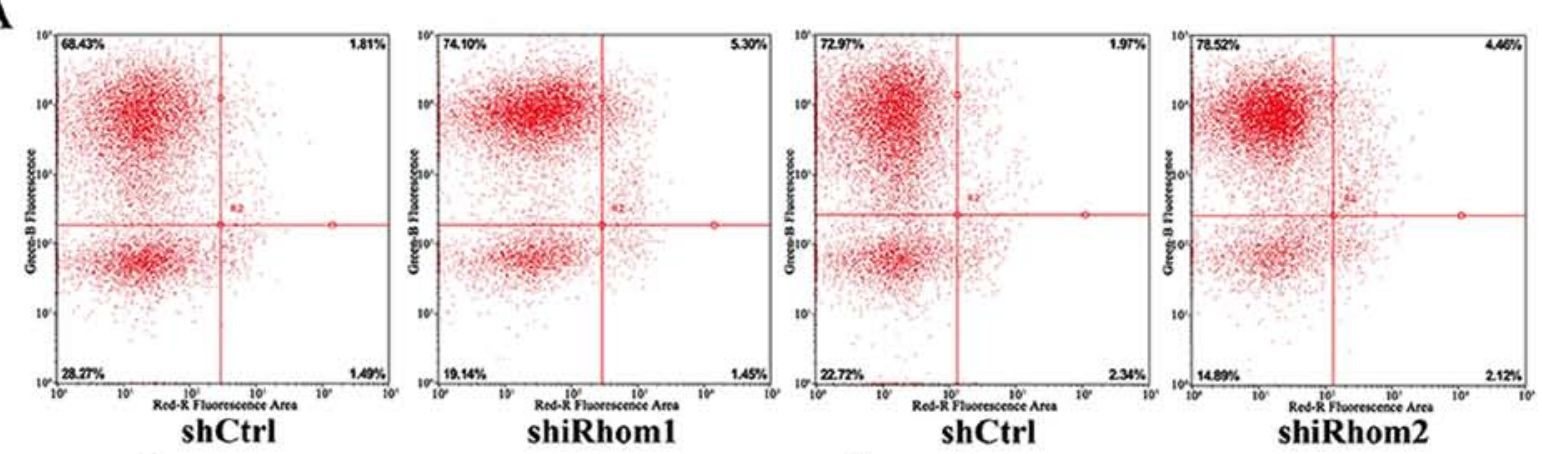

B
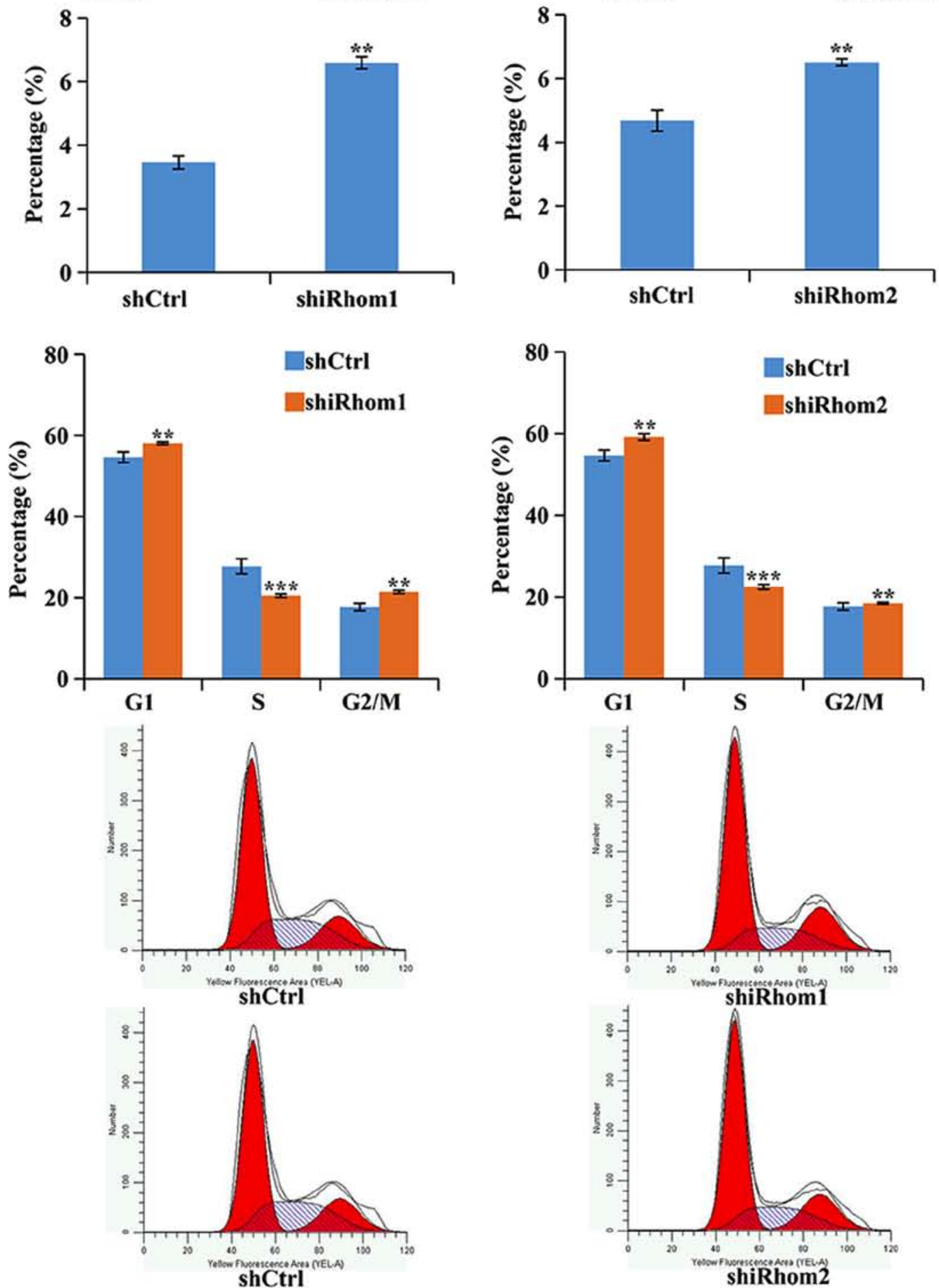

Figure 4. Effect of iRhom1 and iRhom 2 knockdown on HeLa cells. (A) Effect of iRhom1 and iRhom 2 knockdown on apoptosis was presented as flow cytometry, with Annexin V staining and fluorescence-activated cell sorting analysis. (B) Effect of iRhoml and iRhom 2 knockdown on cell cycle progression, based on flow cytometry. ${ }^{* *} \mathrm{P}<0.05,{ }^{* * *} \mathrm{P}<0.01$ relative to shCtrl (iRhom/NC). iRhom1, inactive rhomboid protein $1 ;$ iRhom 2 , inactive rhomboid protein 2. 

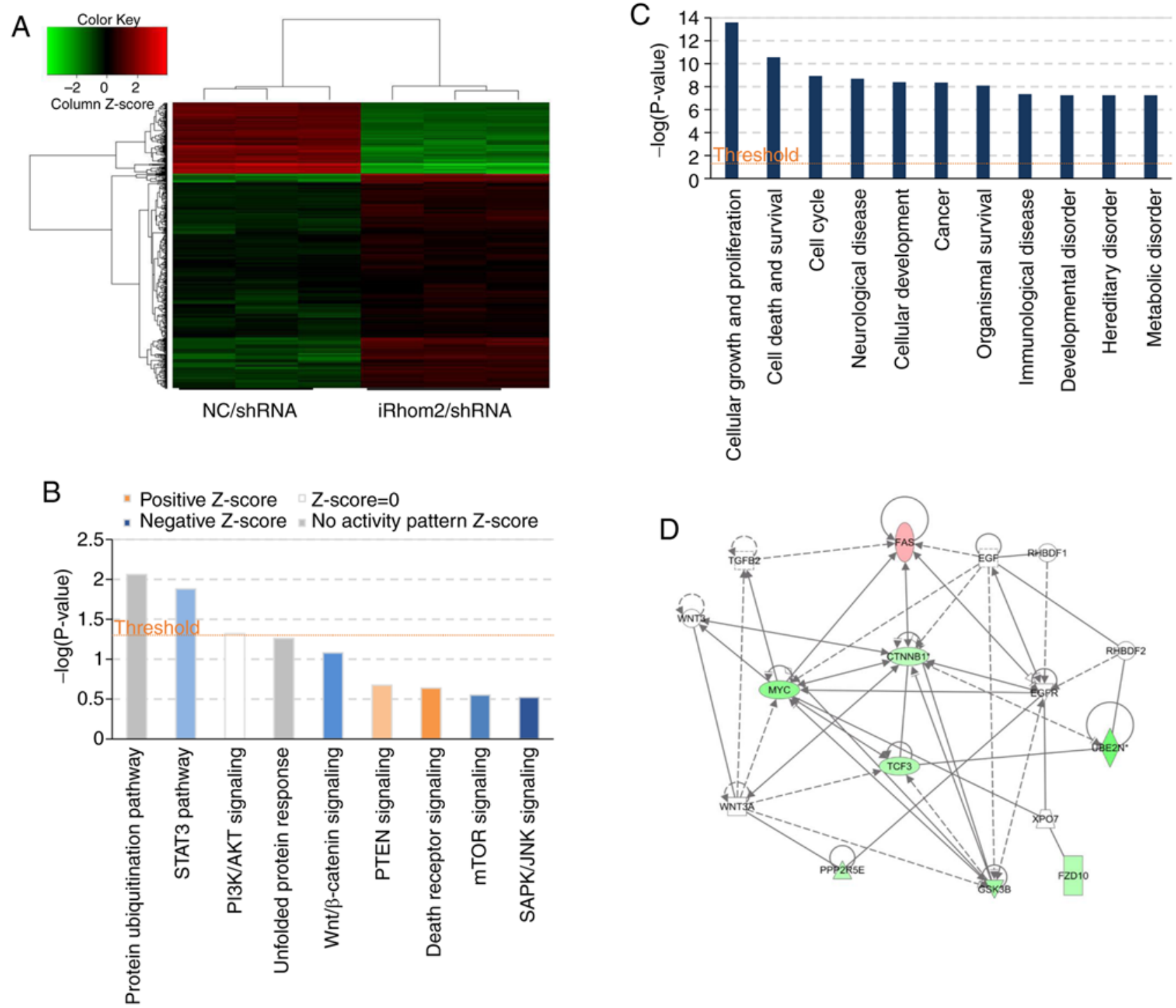

Figure 5. Microarray and IPA analysis of HeLa cells following iRhom 2 knockdown. (A) Heatmap of genes whose expression differed significantly when HeLa cells were transfected with $i R h o m 2 /$ shRNA vs. NC/shRNA. Genes are in rows and samples are in columns; red indicates upregulation and green indicates downregulation in cells expressing iRhom2/shRNA. (B) Enrichment of classical signaling pathways. Stimulated (orange) and inhibited (blue) canonical pathways (from the IPA database), are in descending order by the inverse of $\log (\mathrm{P})$. (C) Dysregulated cellular and molecular functions based on IPA analysis. The top ten disease types/functions are in descending order by the inverse of $\log (\mathrm{P})$. (D) Portion of the gene function network diagram, revealing major molecule-molecule interaction networks in known functional areas. Red indicates upregulation and green indicates downregulation, and brighter colors indicate stronger effects. Line indicates the interaction of two molecules, and full lines indicate stronger effects than imaginary lines. The arrows indicate the direction of action. IPA, Ingenuity Pathway Analysis; iRhom2, inactive rhomboid protein 2.

it remains unknown whether iRhom proteins directly or indirectly interact with the Wnt/ $\beta$-catenin pathway in CC.

The IPA results revealed that iRhom 2 knockdown in HeLa cells altered the expression of five mRNAs $(\beta$-catenin, $F A S$, $M y c, T G F B R 2$ and $G S K 3 \beta$ ) that are involved in Wnt/ $\beta$-catenin signaling. These results were verified by western blotting. Thus, the HeLa experiments demonstrated that iRhoml silencing significantly decreased the expression of $\beta$-catenin, Myc and TGFBR2, and increased the expression of FAS. $i$ Rhom 2 silencing significantly suppressed the expression of $\beta$-catenin, GSK $3 \beta$, and Myc. A previous study of transgenic mice reported that upregulated $\beta$-catenin-dependent signaling accelerated carcinogenesis in HPV-mediated CC (37). There is also evidence that downregulation of a Wnt antagonist (Wnt inhibitory factor 1) reduced apoptosis and promoted growth, invasion, and angiogenesis of CC in vivo (38). DAX1 was revealed to be overexpressed in CC, and promoted cell growth and tumorigenicity by activating the Wnt/ $\beta$-catenin pathway via GSK3 $\beta$ (39). A study on CRC reported that iRhom1 regulated the activity of APC and stimulated EMT and cell proliferation, in part via Wnt/ß-catenin signaling (39). A study on breast cancer cells reported that translocation of accumulated $\beta$-catenin into the nucleus and formation of $\mathrm{TCF} / \mathrm{Lef} / \beta$-catenin complexes induced sequential expression of $c$-MYC, CCDN1, SNAIL1, and MMP2, and this increased cell proliferation, migration, and invasion (40). Our previous study of patients with CC indicated that ADAM17 appears to target matrix metalloproteinase MMP-2 and MMP-9 through the AREG/EMMPRIN and the EGFR-MEK-ERK pathway (11). 

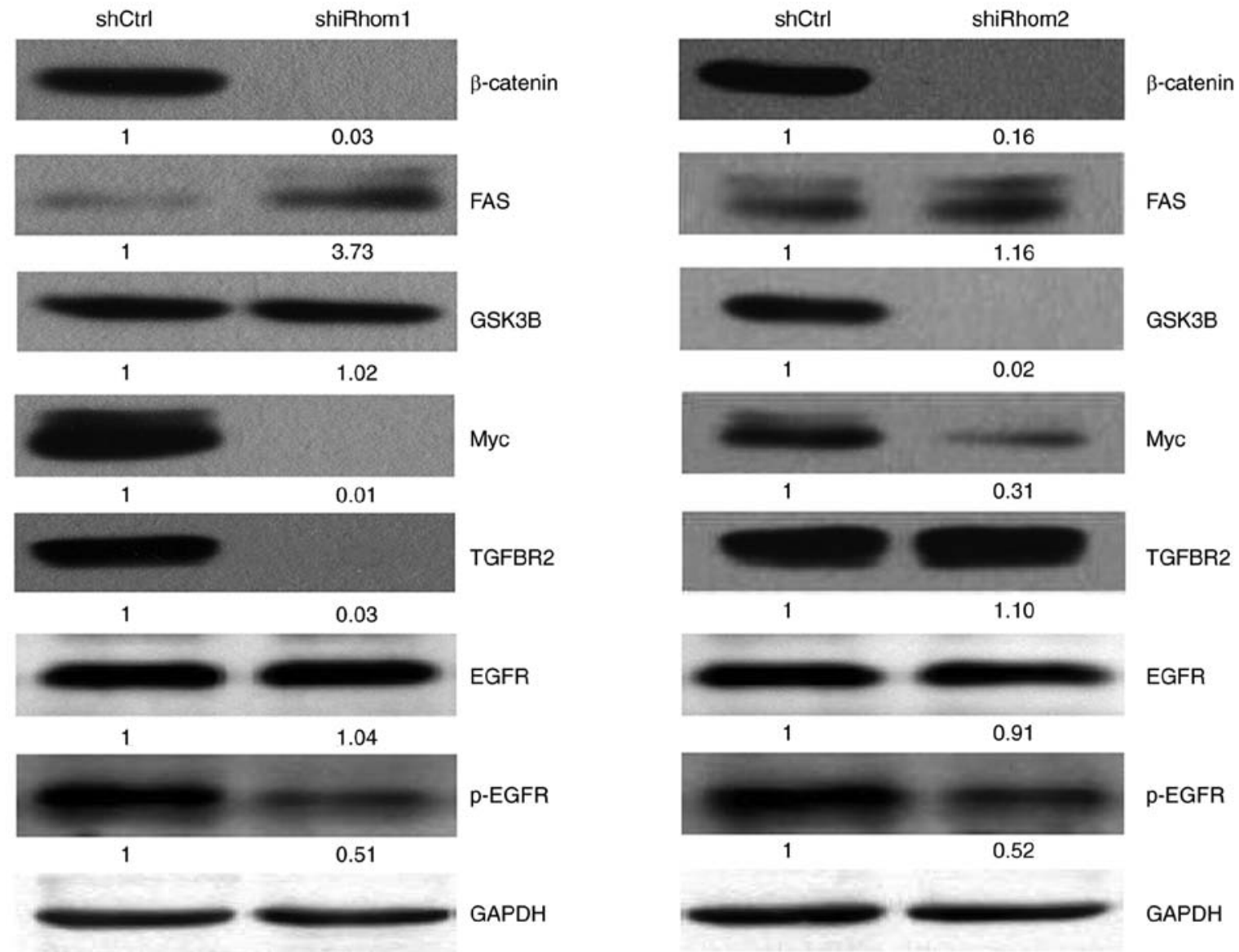

Figure 6. Western blotting of $\beta$-catenin, FAS, GSK3B, Myc, TGFBR2, EGFR and p-EGFR in HeLa cells transfected with shCtrl, shRhom1, or shRhom2. The number under each image is the grayscale value from quantitative analysis. EGFR, epidermal growth factor receptor.

Table III. Genes in the Wnt/ $\beta$-catenin signaling pathway that are downregulated or upregulated following iRhom2 knockdown in HeLa cells (IPA system).

\begin{tabular}{lcc}
\hline Gene & Regulation & Absolute fold change \\
\hline$\beta$-catenin & Down & 1.5029672 \\
GSK3B & Down & 2.0011744 \\
Myc & Down & 2.4327161 \\
TGFBR2 & Up & 1.55694 \\
FAS & Up & 1.7245258 \\
\hline
\end{tabular}

iRhom2, inactive rhomboid protein 2; IPA, Ingenuity Pathway Analysis.

The HeLa experiments revealed that iRhoml knockdown decreased the expression of TGFBR2, and increased the expression of FAS, and that iRhom 2 knockdown suppressed the expression of GSK $3 \beta$. The reason for the different effects of iRhoml and iRhom 2 knockdown on Wnt/3-catenin signaling is unknown. The present study is the first to report different functions of iRhom 1 and iRhom 2 in CC. The downregulation of iRhom proteins could inhibit proliferation, promote apoptosis maybe in part by altering Wnt/ $\beta$-catenin signaling in CC. Our future studies will examine the nature of the interactions of iRhom proteins with these molecules and their effect on remodeling of the ECM.

In conclusion, it was revealed that expression of iRhom1 and iRhom 2 were greater in $\mathrm{CC}$ tissues than adjacent normal tissues, and that upregulation of iRhom1 and iRhom 2 was correlated with certain clinical characteristics and with poor OS. Knockdown of $i$ Rhom 1 and iRhom 2 in HeLa cells inhibited cell growth, disrupted the cell cycle, and promoted apotosis due to alterations in the expression of multiple genes and cancer-associated pathways. Collectively, the present results demonstrated that iRhom proteins act as oncogenes in $\mathrm{CC}$, and therefore have potential use as diagnostic and prognostic biomarkers, as well as therapeutic targets.

\section{Acknowledgements}

The authors would like to thank the Department of Pathology of Fujian Cancer Hospital for their support of the present study.

\section{Funding}

The present study was supported by Grants-in-Aid for Scientific Research 2015J01379 from the Fujian Natural Science Foundation, Fujian Province Health Technology Project (No. 2015-ZQN-ZD-8), and the Science and Technology Program of Fujian Province, China, No. 2018Y2003). 


\section{Availability of data and materials}

The datasets used during the present study are available from the corresponding author upon reasonable request.

\section{Authors' contributions}

QX and CC provided substantial contributions to the conception and design of the work. BL and YL were responsible for the literature search. YL and CG conducted the clinical studies. DZ and YX progressed in the experimental studies. JL and LL provided the data acquisition and carried out the statistical analysis. QX drafted the work, edited the manuscript and revised it critically for important intellectual content. All authors critically revised and approved the final manuscript and agree to be accountable for all aspects of the work in ensuring that questions related to the accuracy or integrity of any part of the work are appropriately investigated and resolved.

\section{Ethics approval and consent to participate}

The Ethics Committee of Fujian Provincial Cancer Hospital which is affiliated with Fujian Medical University, provided approval of this study. Patients provided written informed consent.

\section{Patient consent for publication}

Not applicable.

\section{Competing interests}

The authors declare that they have no competing interests.

\section{References}

1. Global Burden of Disease Cancer Collaboration; Fitzmaurice C, Akinyemiju TF, Al Lami FH, Alam T, Alizadeh-Navaei R, Allen C, Alsharif U, Alvis-Guzman N, Amini E, et al: Global, regional, and national cancer incidence, mortality, years of life lost, years lived with disability, and disability-adjusted life-years for 29 cancer groups, 1990 to 2016: A systematic analysis for the global burden of disease study. JAMA Oncol 4: 1553-1568, 2018.

2. Kim SW, Chun M, Ryu HS, Chang SJ, Kong TW, Lee EJ, Lee YH and Oh YT: Salvage radiotherapy with or without concurrent chemotherapy for pelvic recurrence after hysterectomy alone for early-stage uterine cervical cancer. Strahlenther Onkol 193: 534-542, 2017.

3. Munro A, Codde J, Spilsbury K, Steel N, Stewart CJ, Salfinger SG, Tan J, Mohan GR, Leung Y, Semmens JB, et al: Risk of persistent and recurrent cervical neoplasia following incidentally detected adenocarcinoma in situ. Am J Obstet Gynecol 216: 272.e1-272. e7, 2017.

4. Sturtevant MA, Roark M and Bier E: The Drosophila rhomboid gene mediates the localized formation of wing veins and interacts genetically with components of the EGF-R signaling pathway. Genes Dev 7: 961-973, 1993.

5. Zou H, Thomas SM, Yan ZW, Grandis JR, Vogt A and Li LY: Human rhomboid family-1 gene RHBDF1 participates in GPCR-mediated transactivation of EGFR growth signals in head and neck squamous cancer cells. FASEB J 23: 425-432, 2009.

6. Li J, Bai TR, Gao S, Zhou Z, Peng XM, Zhang LS, Dou DL, Zhang ZS and Li LY: Human rhomboid family-1 modulates clathrin coated vesicle-dependent pro-transforming growth factor $\alpha$ membrane trafficking to promote breast cancer progression. Ebiomedicine 36: 229-240, 2018.
7. Yuan H, Wei R, Xiao Y, Song Y, Wang J, Yu H, Fang T, Xu W and Mao S: RHBDF1 regulates APC-mediated stimulation of the epithelial-to-mesenchymal transition and proliferation of colorectal cancer cells in part via the Wnt/ $\beta$-catenin signalling pathway. Exp Cell Res 368: 24-36, 2018.

8. Adrain C, Zettl M, Christova Y, Taylor N and Freeman M: Tumor necrosis factor signaling requires iRhom 2 to promote trafficking and activation of TACE. Science 335: 225-228, 2012.

9. McIlwain DR, Lang PA, Maretzky T, Hamada K, Ohishi K, Maney SK, Berger T, Murthy A, Duncan G, Xu HC, et al: iRhom2 regulation of TACE controls TNF-mediated protection against Listeria and responses to LPS. Science 335: 229-232, 2012.

10. Blaydon DC, Etheridge SL, Risk JM, Hennies HC, Gay LJ, Carroll R, Plagnol V, McRonald FE, Stevens HP, Spurr NK, et al: RHBDF2 mutations are associated with tylosis, a familial esophageal cancer syndrome. Am J Hum Genet 90: 340-346, 2012.

11. Xu Q, Ying M, Chen G, Lin A, Xie Y, Ohara N and Zhou D: ADAM17 is associated with EMMPRIN and predicts poor prognosis in patients with uterine cervical carcinoma. Tumour Biol 35: 7575-7586, 2014.

12. Zettl M, Adrain C, Strisovsky K, Lastun V and Freeman M: Rhomboid family pseudoproteases use the ER quality control machinery to regulate intercellular signaling. Cell 145: 79-91, 2011.

13. Yan Z, Zou H, Tian F, Grandis JR, Mixson AJ, Lu PY and Li LY: Human rhomboid family-1 gene silencing causes apoptosis or autophagy to epithelial cancer cells and inhibits xenograft tumor growth. Mol Cancer Ther 7: 1355-1364, 2008.

14. Arcidiacono P, Webb CM, Brooke MA, Zhou H, Delaney PJ, Ng KE, Blaydon DC, Tinker A, Kelsell DP and Chikh A: p63 is a key regulator of iRHOM2 signalling in the keratinocyte stress response. Nat Commun 9: 1021, 2018.

15. Ishimoto T, Miyake K, Nandi T, Yashiro M, Onishi N, Huang KK, Lin SJ, Kalpana R, Tay ST, Suzuki Y, et al: Activation of transforming growth factor beta 1 signaling in gastric cancer-associated fibroblasts increases their motility, via expression of rhomboid 5 homolog 2 , and ability to induce invasiveness of gastric cancer cells. Gastroenterology 153: 191-204.e16, 2017.

16. Wojnarowicz PM, Provencher DM, Mes-Masson AM and Tonin PN: Chromosome 17q25 genes, RHBDF2 and CYGB, in ovarian cancer. Int J Oncol 40: 1865-1880, 2012.

17. Li X, Maretzky T, Weskamp G, Monette S, Qing X, Issuree PD, Crawford HC, McIlwain DR, Mak TW, Salmon JE and Blobel CP: iRhoms 1 and 2 are essential upstream regulators of ADAM17-dependent EGFR signaling. Proc Natl Acad Sci USA 112: 6080-6085, 2015.

18. Etheridge SL, Brooke MA, Kelsell DP and Blaydon DC: Rhomboid proteins: A role in keratinocyte proliferation and cancer. Tissue Cell Res 351: 301-307, 2013.

19. Zhang Y, Li Y, Yang X, Wang J, Wang R, Qian X, Zhang W and Xiao W: Uev1A-Ubc13 catalyzes K63-linked ubiquitination of RHBDF2 to promote TACE maturation. Cell Signal 42: 155-164, 2018.

20. Hosur V, Johnson KR, Burzenski LM, Stearns TM, Maser RS and Shultz LD: Rhbdf 2 mutations increase its protein stability and drive EGFR hyperactivation through enhanced secretion of amphiregulin. Proc Natl Acad Sci USA 111: E2200-E2209, 2014

21. Siggs OM, Grieve A, Xu H, Bambrough P, Christova Y and Freeman M: Genetic interaction implicates iRhom 2 in the regulation of EGF receptor signalling in mice. Biol Open 3: 1151-1157, 2014

22. Vembar SS and Brodsky JL: One step at a time: Endoplasmic reticulum-associated degradation. Nat Rev Mol Cell Biol 9: 944-957, 2008

23. Wang $\mathrm{R}$, Li $\mathrm{Y}$, Tsung $\mathrm{A}$, Huang $\mathrm{H}$, Du $\mathrm{Q}$, Yang $\mathrm{M}$, Deng M, Xiong S, Wang X, Zhang L, et al: iNOS promotes $\mathrm{CD} 24^{+} \mathrm{CD} 133^{+}$liver cancer stem cell phenotype through a TACE/ADAM17-dependent Notch signaling pathway. Proc Natl Acad Sci USA 115: E10127-E10136, 2018.

24. Cataisson C, Michalowski AM, Shibuya K, Ryscavage A, Klosterman M, Wright L, Dubois W, Liu F, Zhuang A, Rodrigues $\mathrm{KB}$, et al: MET signaling in keratinocytes activates EGFR and initiates squamous carcinogenesis. Sci Signal 9: ra62, 2016.

25. Nusse $R$ and Clevers $H$ : Wnt/ $\beta$-catenin signaling, disease, and emerging therapeutic modalities. Cell 169: 985-999, 2017.

26. Gonzalez DM and Medici D: Signaling mechanisms of the epithelial-mesenchymal transition. Sci Signal 7: re 8, 2014.

27. McCrea PD and Gottardi CJ: Beyond $\beta$-catenin: Prospects for a larger catenin network in the nucleus. Nat Rev Mol Cell Biol 17: 55-64, 2016. 
28. Stamos JL and Weis WI: The $\beta$-catenin destruction complex. Cold Spring Harb Perspect Biol 5: a007898, 2013.

29. Ueda T, Tsubamoto H, Inoue K, Sakata K, Shibahara H and Sonoda T: Itraconazole modulates hedgehog, WNT/ $\beta$-catenin, as well as Akt signalling, and inhibits proliferation of cervical cancer cells. Anticancer Res 37: 3521-3526, 2017.

30. Mazieres J, He B, You L, Xu Z, Lee AY, Mikami I, Reguart N, Rosell R, McCormick F and Jablons DM: Wnt inhibitory factor-1 is silenced by promoter hypermethylation in human lung cancer. Cancer Res 64: 4717-4720, 2004.

31. Takigawa Y and Brown AM: Wnt signaling in liver cancer. Curr Drug Targets 9: 1013-1024, 2008.

32. Khramtsov AI, Khramtsova GF, Tretiakova M, Huo D, Olopade OI and Goss KH: Wnt/beta-catenin pathway activation is enriched in basal-like breast cancers and predicts poor outcome. Am J Pathol 176: 2911-2920, 2010.

33. Lu D, Zhao Y, Tawatao R, Cottam HB, Sen M, Leoni LM, Kipps TJ, Corr M and Carson DA: Activation of the Wnt signaling pathway in chronic lymphocytic leukemia. Proc Natl Acad Sci USA 101: 3118-3123, 2004.

34. Chung MT, Lai HC, Sytwu HK, Yan MD, Shih YL, Chang CC, Yu MH, Liu HS, Chu DW and Lin YW: SFRP1 and SFRP2 suppress the transformation and invasion abilities of cervical cancer cells through Wnt signal pathway. Gynecol Oncol 112: 646-653, 2009.

35. Lin YW, Chung MT, Lai HC, De Yan M, Shih YL, Chang CC and Yu MH: Methylation analysis of SFRP genes family in cervical adenocarcinoma. J Cancer Res Clin Oncol 135: 1665-1674, 2009.
36. Lee J, Yoon YS and Chung JH: Epigenetic silencing of the WNT antagonist DICKKOPF-1 in cervical cancer cell lines. Gynecol Oncol 109: 270-274, 2008.

37. Bulut G, Fallen S, Beauchamp EM, Drebing LE, Sun J, Berry DL, Kallakury B, Crum CP, Toretsky JA, Schlegel R and Üren A: Beta-catenin accelerates human papilloma virus type-16 mediated cervical carcinogenesis in transgenic mice. PLoS One 6: e27243, 2011.

38. Ramachandran I, Thavathiru E, Ramalingam S, Natarajan G, Mills WK, Benbrook DM, Zuna R, Lightfoot S, Reis A, Anant S and Queimado L: Wnt inhibitory factor 1 induces apoptosis and inhibits cervical cancer growth, invasion and angiogenesis in vivo. Oncogene 31: 2725-2737, 2012.

39. Liu XF, Li XY, Zheng PS and Yang WT: DAX1 promotes cervical cancer cell growth and tumorigenicity through activation of Wnt $/ \beta$-catenin pathway via GSK3 $\beta$. Cell Death Dis 9: $339,2018$.

40. Perez-Yepez EA, Ayala-Sumuano JT, Lezama R and Meza I: A novel $\beta$-catenin signaling pathway activated by IL- $1 \beta$ leads to the onset of epithelial-mesenchymal transition in breast cancer cells. Cancer Lett 354: 164-171, 2014. International (CC BY-NC-ND 4.0) License. 